\title{
Effect of unilateral and bilateral eyestalk ablation in Litopenaeus vannamei male and female on several metabolic and immunologic variables
}

\author{
Juan Carlos Sainz-Hernández ${ }^{a,{ }^{*}}$, Ilie S. Racotta ${ }^{\text {b, d }}$, Silvie Dumas ${ }^{c}$ and Jorge Hernández- \\ López $^{b}$
}

\footnotetext{
${ }^{a}$ Centro Interdisciplinario de Investigación para el Desarrollo Integral Regional Unidad Sinaloa (CIIDIR-Sinaloa), Boulevard Juan de Dios Bátiz Paredes No. 250, Guasave, Sinaloa, 81101, Mexico

${ }^{\mathrm{b}}$ Centro de Investigaciones Biológicas del Noroeste (CIBNOR), Mar Bermejo No. 195, Col. Playa Palo de Santa Rita, La Paz, B.C.S. 23090, Mexico

${ }^{c}$ Centro Interdisciplinario de Ciencias Marinas (CICIMAR), Av. IPN s/n, Col. Playa Palo de Santa Rita, La Paz, B.C.S. 23090, Mexico

d Ifremer, UMR M100, Laboratoire de Physiologie des Invertébrés, BP 70, Centre de Brest, 29280 Plouzané, France
}

\author{
*: Corresponding author: Juan Carlos Sainz-Hernández, Tel.: +52 687872 9626x87636; fax: +52 687 \\ 872 9625, email address : jsainz@ipn.mx
}

\begin{abstract}
:
Eyestalk ablation is the most common procedure to induce gonadic maturation in commercial hatcheries of penaeid shrimp. In addition to reproduction, other physiological and metabolic processes are affected by removal of the X-organ sinus gland complex located in the eyestalk. In this study, the effect of unilateral and bilateral eyestalk ablation on the concentration of several hemolymph metabolites and phenoloxidase system in female and male shrimp was investigated. As a consequence of reducing or suppressing molt-inhibiting hormone $(\mathrm{MIH})$ production, the duration of the molting cycle was significantly shorter in eyestalk-ablated shrimp: bilaterally (10 days), unilaterally (17 days), and shrimp that were not ablated (24 days). Mortality was significantly higher in unilaterally $(35 \%)$ and bilaterally $(68 \%)$ ablated shrimp than in untreated shrimp (2\%), probably caused by impairment of several physiological functions mediated by hormones from the eyestalk and direct injury of the nervous system. Males and females were affected differently by eyestalk ablation in terms of concentrations of glucose, triglycerides, and protein in hemolymph. Glucose and lactate levels were lower in bilaterally ablated shrimp, as expected by the role of crustacean hyperglycemic hormone in glucose metabolism. Cholesterol and hemocyte count were not significantly different among the three treatments. Prophenoloxidase and phenoloxidase activities were significantly lower in bilaterally, but not in unilaterally ablated shrimp. This could suggest an endocrine control of this mechanism of the effector immune response or reflect the level of physiological trauma caused by bilateral eyestalk ablation in this species.
\end{abstract}

Keywords: Hemolymph metabolites; Phenoloxidase; Shrimp; Sinus gland 

60 similar role. 1988).

\section{Introduction}

Eyestalk ablation (hereafter called ablation) has been used since 1970 to improve the aquaculture production of Penaeus spp. larvae (Bray and Lawrence, 1992). Besides improving reproductive performance, there is evidence of other metabolic consequences that are not fully understood. The X-organ sinus gland complex, located in the eyestalks, is the principal neuroendocrine gland in crustaceans (Beltz, 1988; Chang, 1992). In this gland, hormones are synthesized, stored, and secreted to the hemolymph to regulate several metabolic processes (Chang, 1992). The most studied processes are vitellogenesis (Fingerman, 1995; Palacios et al., 1999), food intake, digestion, and nutrient transport (Rosas et al., 1995), molting (Chang and O’Connor, 1988), metabolism of lipids (Teshima et al., 1988; Santos et al., 1997), regulation of glucose and proteins in hemolymph (Santos and Keller, 1993a,b; Teshima et al., 1988; Chen and Cheng, 1995), hydromineral balance, regeneration and pigment production (Keller and Sedlmeier,

Despite the numerous studies of the prophenoloxidase (proPO) activating system (for review, see Söderhäll and Smith, 1986; Sritunyalucksana and Söderhäll, 2000), little information exists about its endocrine control. Perazzolo et al. (2002) observed a decrease in total phenoloxidase (PO) activity seven days after ablation of shrimp, but explained the decrease because of stress, instead of endocrine control. In insects, it is known that ecdysone modulates the expression of proPO-activating enzyme at the mRNA level (Ahmed et al., 1999; Zou et al., 2005). In crustaceans, ecdysone from the Y-organ is under the control of the sinus gland (Chang and O'Connor, 1988) and could have a 
Most of the studies related to the removal of eyestalks in penaeid shrimp have

62 focused on reproduction (for reviews, see Bray and Lawrence, 1992; Racotta et al.,

63 2003). Only a few studies analyzed the metabolic or immunologic consequences (Rosas

64 et al., 1993; Palacios et al., 1999; Perazzolo et al., 2002; Maggioni et al., 2004). Rosas et

65

66

67

68

69

70

71

72

73

74

75

76

77 $(2$

al. (1993) found differences between the sexes in energy balance after ablation, although these differences were related to the different reproductive efforts of males and females.

In this study, the effect of unilateral and bilateral ablation on biochemical composition of the hemolymph and related immune system variables was analyzed in non-reproductive Litopenaeus vannamei females and males.

\section{Materials and methods}

\subsection{Experimental conditions}

A total of 100 female and male whiteleg shrimp L. vannamei $(15.5 \pm 1.5 \mathrm{~g})$ were transferred to circular tanks $(1.5 \mathrm{~m}$ diameter $\times 0.8 \mathrm{~m}$ high $)$ at a density of 16 shrimp per tank, in a closed circulating system at $24{ }^{\circ} \mathrm{C}$ and salinity of 34 with $400 \%$ daily water exchange and a $12 \mathrm{~h}: 12 \mathrm{~h}$ photoperiod. Shrimp were fed every morning with a commercial pellet diet containing $40 \%$ protein, $7 \%$ lipids, $10 \%$ moisture, and $7 \%$ ash (Piasa, La Paz, México) and before darkness with fresh squid. Shrimp were individually marked by different cutting of the uropods, which allows 16 different combinations. After molting, these marks are still present in the exuviae, allowing the identification of molted individuals (Racotta and Hernández-Herrera, 2000).

\subsection{Eyestalk ablation and sampling in relation to the molt cycle}


Two days after ecdysis, shrimp were ablated unilaterally (left eyestalk only) or

bilaterally (both eyestalks) by cutting the eyestalks under water at the base of the peduncle and applying pressure to the wound for $15 \mathrm{~s}$ to minimize fluid loss and help coagulation. Control animals (not ablated) were manipulated in a similar way two days after ecdysis. Overnight fasting shrimp were sampled between 08:00 and 09:00 h, hemolymph was withdrawn from the ventral sinus with a $1.0 \mathrm{ml}$ syringe containing a shrimp salt solution with EDTA as the anticoagulant $(450 \mathrm{mM} \mathrm{NaCl}, 10 \mathrm{mM} \mathrm{KCl}, 10$ mM hepes, and $10 \mathrm{mM}$ EDTA-Na 2 at pH 7.3) (Vargas-Albores et al., 1993). Hemolymph was kept on ice for all measurements. Only intermolt shrimps were sampled, based on the individual's last molting and observation of uropods (Chang et al., 1988).

\subsection{Biochemical analyses}

Glucose, lactate, triglycerides, and cholesterol were measured with commercial kits from Merck and Sigma. Total proteins were determined by the technique described by Bradford (1976). These protocols were standardized at $450 \mathrm{mM}$ salinity in a microplate reader, using appropriate calibration curves for each variable (Palacios et al., 1999). For each variable, 10 to $50 \mu \mathrm{l}$ of a sample, depending on the particular analysis, were mixed with $200 \mu \mathrm{l}$ reagent solution and incubated at $24{ }^{\circ} \mathrm{C}$ for 10 to $30 \mathrm{~min}$, depending on maximum reaction and stability of each analysis. Absorbance was read at $492 \mathrm{~nm}$ for glucose, triglycerides, and cholesterol, at $560 \mathrm{~nm}$ for lactate, and $595 \mathrm{~nm}$ for proteins.

\subsection{Total hemocyte count}


Hemolymph was diluted 1:10 with sterile shrimp salt solution. From this dilution, 108 hemocytes were counted in triplicate with a Neubauer chamber under a light microscope

109 and total hemocyte count was reported as the number of hemocytes $\mathrm{ml}^{-1}$ of hemolymph.

\subsection{Determination of proPO content and PO activity}

Hemocytes were separated from plasma by centrifugation at $3000 \mathrm{~g}$ for $3 \mathrm{~min}$.

113 Hemocytes were suspended in $450 \mu \mathrm{l}$ cacodylate buffer $(10 \mathrm{mM}$ sodium cacodilate at $\mathrm{pH}$

114 7). PO activity was determined by recording the formation of dopachrome from L-

115 dihydroxiphenylalanine, a reaction catalyzed by PO (Hernández-López et al., 1996). Fifty

$116 \mu$ l cacodilate buffer were added to $50 \mu \mathrm{l}$ plasma and then $50 \mu \mathrm{L}$-dopa $\left(3 \mathrm{mg} \mathrm{ml}^{-1} \mathrm{dH}_{2} \mathrm{O}\right)$.

117 The solution was incubated $10 \mathrm{~min}$ at $25^{\circ} \mathrm{C}$, then $800 \mu \mathrm{l}$ cacodylate buffer was added and

118 the absorbance was measured. Cacodylate buffer was used as a control. Total activity was

119 expressed as the change in absorbance at $492 \mathrm{~nm} \mathrm{~min}^{-1} \mathrm{ml}^{-1}$ of hemolymph sampled.

120 To determine whole PO activity (activated proPO + PO), the proPO sample was

121 first activated with trypsin $\left(0.1 \mathrm{mg} \mathrm{ml}^{-1}\right.$ in distilled $\left.\mathrm{H}_{2} \mathrm{O}\right)$. Then, proPO content was

122 calculated as the absorbance obtained for whole PO activity from samples incubated with

123 trypsin minus the absorbance obtained for PO activity from samples incubated without

124 trypsin. Originally, proPO and PO were analyzed separately in the plasma and the cellular 125 pellet; however, data obtained for both fractions were summed to correct for accidental 126 degranulation or rupture of hemocytes. 
Normal distribution and homoscedasticity were examined for each group of data.

130 The effect of ablation treatment and sex were analyzed by two-way ANOVA. When

131 significant differences were found by ANOVA, data were analyzed with an a posteriori

132 Tukey test for different sample size. Only when a significant interaction between ablation

133 treatment and sex was obtained, individual means (each ablation treatment-sex

134 combination) were compared; otherwise only global means (i.e. pooled means for 135 ablation treatment or sex) were compared.

\section{Results}

Duration of the molt cycle significantly decreased with ablation: bilateral took 10 days and unilateral took 17 days, while the control group took 24 days ( $\mathrm{P}<0.01$; Fig. 1 ) and with no significant differences between sexes. Mortality was $2 \%$ for the control group, $33 \%$ in the unilaterally ablated group, and 68\% in the bilaterally ablated group, again, without significant differences between sexes (not shown).

A significant interaction between sex and ablation $(\mathrm{P}<0.05)$ was obtained for the concentration of glucose (Fig. 2a). Compared to controls, glucose levels increased in unilaterally ablated males and decreased in unilaterally ablated females. In general, bilaterally ablated shrimp had lower levels of glucose, compared to control group (females) or unilaterally ablated group (males). Concentration of lactate was significantly higher in females than in males (main effect of sex, $\mathrm{P}<0.001$; Males $3.5 \pm 0.43 \mathrm{mg} \mathrm{dl}^{-1}$, females $6.5 \pm 0.7 \mathrm{mg} \mathrm{dl}^{-1}$ ). Lactate concentrations were lower in the bilaterally ablated group compared to the unilateral ablated group, with intermediate levels in the control group (Fig. 2b; main effect of ablation treatment, $\mathrm{P}<0.001$ ). 
For concentration of triglycerides, ablation affected females and males differently, as shown by a significant interaction $(\mathrm{P}<0.05$; Fig 3a). Within the control group, females had significantly higher levels than males. Triglycerides were lower in unilaterally ablated females, compared to the control group, but no effect was observed in ablated males. No significant effects were observed in cholesterol concentration (Fig. 3b).

A significant interaction $(\mathrm{P}<0.05)$ was also detected for the concentration of protein (Fig. 4). In the control group, protein was significantly lower in females than in males, whereas the opposite effect occurred in unilaterally ablated shrimp. In females, unilateral ablation decreased protein levels, while in males, protein levels were increased by unilateral ablation.

Content of proPO and activity of PO were significantly lower in bilaterally ablated shrimp compared to the control group or to unilaterally ablated shrimp (main effect of ablation, $\mathrm{P}<0.05$; Figs. 5a and 5b). Sex did not affect proPO or PO; interactions were not significant. Total hemocyte count was not significantly affected by ablation or sex, although a trend toward a decrease with degree of ablation was observed (Fig. 5c).

\section{Discussion}

As in other reports, the duration of the molt cycle decreased in both sexes of whiteleg shrimp as an effect of ablation. Similar results were obtained by Chan et al. (1990) with shrimp of the same size but maintained at $22^{\circ} \mathrm{C}$, rather than $24{ }^{\circ} \mathrm{C}$, where the molt cycle duration for intact, unilaterally and bilaterally ablated shrimp was 23.4, 15.9, and 9.1 days, respectively. However, in two related species (blue shrimp Litopenaeus stylirostris and white shrimp L. setiferus) maintained at higher temperatures $\left(27-29^{\circ} \mathrm{C}\right)$, 
175 the effect of ablation was less pronounced: the molt cycle was 13.6 days in intact shrimp

176 and 11.5 days in unilaterally ablated shrimp (Robertson et al., 1987). The decrease in

177 molt cycle duration following ablation is mainly attributed to the lower concentration of

178 molt-inhibiting hormone caused by ablation. This hormone exerts an inhibitory action on

179 ecdysteroids biosynthesis (Chang and O'Connor, 1988; Lachaise et al., 1993). In ablated

180 shrimp, 20-hydroecdysone (20E) is synthesized and secreted at a higher rate. Studies with

181 L. stylirostris_(Gendrop-Funes and Valenzuela-Espinosa, 1995) and other crustaceans

182 (Carlisle, 1953) failed to obtain a decrease in molt cycle duration after ablation. Chan et

183 al. (1990) suggested that this was a consequence of the molt stage or reproductive stage

184 of the shrimp at the time of ablation. According to our results, the duration of the molt

185 cycle after ablation is the same in females and males. Sexual dimorphism is apparent in

186 shrimp $>20 \mathrm{~g}$ (Otoshi et al., 2003) or when sexual maturity is attained at $\sim 30 \mathrm{~g}$ (Racotta et

187 al., 2003). Therefore, possible differences in duration of the molt cycle between females

188 and males would occur in shrimp larger than those used in our study.

189 Mortality was directly related to the degree of ablation. This was expected,

190 considering the strong physiological stress caused by partial or total removal of the main

191 endocrine gland, the X-organ sinus gland complex. Ablation not only removes this organ

192 complex, it produces severe trauma, destroys a mayor portion of the nervous system, and

193 renders the animal blind (Chang and O'Connor, 1988; Chang, 1989).

$194 \quad$ Function of the humoral and cellular defense system has been widely investigated

195 in crustaceans and insects (Söderhäll and Smith, 1986; Olafsen, 1988; Johanson and

196 Söderhäll, 1989; Vargas-Albores, 1995; Hernández-López et al., 1996; Moullac et al.,

197 1997). Recent studies in insects indicate that several neuroendocrine systems modulate 
198 the humoral and cellular defense system. In unilaterally ablated female Farfantepenaeus

199 paulensis, a decrease in total hemocyte count was observed (Perazzolo et al., 2002). In $L$.

200 vannamei, the decline was not significant (Maggioni et al., 2004); in our study, only a

201 non-significant trend, related to the degree of ablation was observed for males. In

202 Drosophila melanogaster, Sorentino et al. (2002) found that the lack of ecdysteroids

203 compromised the cellular immune responses reducing hemocytes proliferation and 204 encapsulation.

205 Beside the evidence that 20E affect cellular activity, Ahmed et al. (1999)

206 demonstrated that 20E up-regulates the expression of proPO gene in Anopheles gambiae.

207 In our study, and as suggested by duration of the molt cycle, ablated shrimp probably

208 have higher levels of $20 \mathrm{E}$ that should, in turn, increase the level of proPO. However, we

209 observed a decline in proPO in bilaterally ablated shrimp. Ahmed et al. (1999) and

210 Müller et al. (1999) found different proPO genes in insects and demonstrated that 20E

211 can stimulate, inhibit, or not affect the expression of the different proPO genes. The

212 decline in proPO in ablated shrimp in our study could be an inhibitory action of $20 \mathrm{E}$ on

213 the expression of proPO gene(s) in hemocytes. Alternatively, a decline in one or several

214 particular hormones from the eyestalk with a putative positive effect on a proPO gene

215 could also be involved and remains to be investigated.

216 The non-significant decrease of hemocytes in bilaterally ablated shrimp,

217 particularly in males, could also contribute to the reduced proPO activity produced by

218 semi-granular and granular hemocytes (Sritunyalucksana and Söderhäll, 2000).

219 Moreover, reduced PO activity in bilaterally ablated shrimp could be a direct

220 consequence of lower levels of proPO or decreased activity of a proPO-activating 
enzyme, a serine proteinase that converts proPO into PO (Sritunyalucksana and Söderhäll, 2000). According to Zou et al. (2005), 20E reduced the mRNA levels of the proPO-activating proteinase in Manduca sexta. Perazzolo et al. (2002) found reduced whole PO (proPO + PO) in unilaterally ablated Farfantepenaeus paulensis, but Maggioni et al. (2004) found no effect in L. vannamei. In our study, this effect occurred only in bilaterally ablated shrimp.

Beside the participation of PO in the internal defense system, the enzyme participates in the process of cuticular melanization in crustaceans (Benjakul et al., 2005) and insects (Hiruma and Riddiford, 1993). The acceleration of the molting process caused by ablation presumably produces increased melanin production through the PO system. However, it is not known if PO in hemocytes participates in melanin incorporated in the exoskeleton. In insects, the PO responsible for cuticular melanization is produced in the epidermis (Hiruma and Riddiford, 1993).

It is well known that crustacean hyperglycemic hormone $(\mathrm{CHH})$ secreted from the sinus gland located in the eyestalk stimulates hyperglycemia (Santos and Keller, 1993a), but it is not clear if $\mathrm{CHH}$ controls the baseline levels of circulating glucose because ablation does not necessarily modify these levels. In lobsters Panulirus argus, only bilaterally, but not unilaterally ablated specimens had lower levels of hemolymph glucose (Diaz-Iglesias et al., 1987). This suggests that some $\mathrm{CHH}$ is needed to maintain a certain level of glucose. Controversial results have been reported for the glucose concentration in the crab Chasmagnathus granulate: no effect was reported by Santos and Colares (1986), whereas Santos et al. (1988) reported a decreased in glucose concentration 24 hours after bilateral ablation. The last authors attributed the discrepancy to the method used for 
244 glucose analysis, since the reduced levels occurred only when a specific enzymatic

245 procedure was used. However, utilizing the same method used in our study, no effect of

246 bilateral ablation was observed in Carcinus maenas (Lüschen et al., 1993; Santos and

247 Keller, 1993c) and a slight decrease occurred in Orconectes limosus (Santos and Keller,

248 1993c) and kuruma shrimp Marsupenaeus japonicus (Kuo et al., 1995). In our study,

249 lower glucose concentrations occurred in unilaterally and bilaterally ablated females and

250 higher concentrations occurred in unilaterally ablated males. Absence of a clear relation

251 between glucose levels and degree of ablation suggests that $\mathrm{CHH}$ is not directly involved

252 in maintaining glucose levels, as originally suggested by Santos and Colares (1986). In

253 addition to $\mathrm{CHH}$, monoamines, such as catecholamines and serotonin produces clear

254 hyperglycemic responses in ablated Carcinus maenas (Lüschen et al., 1993), suggesting

255 that others neuroendocrine mechanisms are involved in glucose regulation and

256 metabolism without participation of $\mathrm{CHH}$. In contrast to glucose, a low lactate

257 concentration in bilaterally ablated shrimps in our study could result from suppression of

258 the principal source of $\mathrm{CHH}$, which apparently stimulates anaerobic glycolysis with

259 lactate production (Santos and Keller, 1993b).

260 Hormones from the sinus gland are also involved in lipid metabolism, as clearly

261 indicated by the use of ablation to induce gonad development (for reviews, see Bray and

262 Lawrence, 1992; Racotta et al., 2003), a process involving accumulation of lipids in

263 gonads (Teshima et al., 1988; Palacios et al., 1999). The general effects of ablation on

264 reproduction, including mobilization of lipids from the hepatopancreas to the gonad, are

265 mainly attributed to the concomitant reduction in the levels of gonad inhibiting hormone

266 produced by the sinus gland. However, it was also suggested that $\mathrm{CHH}$ stimulates lipid 
267 mobilization from the hepatopancreas with a concomitant increase in several lipid classes 268 in the hemolymph (Santos et al., 1997). In Carcinus maenas males, ablation produces a 269 significant decrease of total lipids, but not of triglycerides in the hemolymph (Santos et 270 al., 1997). In our study, unilateral, but not bilateral, ablation significantly decreased 271 triglycerides levels only in hemolymph of females. Lack of a relationship between 272 triglyceride levels and the degree of ablation does not allow a clear interpretation of our 273 results that addresses possible antagonic effects of $\mathrm{CHH}$ and $\mathrm{GIH}$ on metabolism of 274 lipids.

In previous studies, contradictory results were obtained for the effect of ablation on protein levels in hemolymph of penaeid shrimp. Perazzolo et al. (2002) reported that 277 protein levels decreased by $50 \%$ in unilaterally ablated Farfantepenaeus paulensis 278 females. In contrast, Maggioni et al. (2004) reported a non-significant increase in protein 279 of $27 \%$ in unilaterally ablated L. vannamei females. In our study, unilaterally ablated 280 males and females produced opposite effects, and thus should be discussed together with 281 sex-dependent effects.

Several effects of ablation were related to sex and differences between sexes were 283 observed in the control group. Few studies have systematically compared metabolic 284 responses between males and females. Chen and Cheng (1993) did not find differences in 285 protein and hemocyanin levels between females and males in southern pink shrimp 286 Marsupenaeus japonicus. Rosas et al. (1993) observed that ablation in Farfantepenaeus 287 notialis increased ingestion of food and assimilation rates to a greater extent in females 288 than males. Moreover, a more efficient use of energy in ablated females than in ablated 289 males was apparently related to different energy requirements to support ablation-induced 
290 gonad development (Rosas et al., 1993). Although, shrimp in our study had not reached 291 sexual maturity, it seems that metabolic differences can occur before maturity. Higher levels of lactate were observed in females in all treatments. Females could 293 be more susceptible to stress during the sampling procedure, since increased lactate is a 294 typical stress response in penaeid shrimp (Racotta and Palacios, 1998). Lower glucose 295 levels in unilaterally ablated females, in contrast to males, could be related to higher 296 glucose use in anaerobic glycolysis, as reflected by the marked increase in lactate levels

297 in unilaterally ablated females. For the control group, triglycerides levels were lower, 298 whereas protein was higher in males than in females. Both components represent

299 circulating reserves that could satisfy increased tissue metabolism induced by ablation as 300 suggested by oxygen consumption (Nan et al., 1995). If so, the major circulating reserve 301 for each sex should be preferentially used, although it would not explain the increase in 302 protein in unilaterally ablated females.

\section{5. Conclusions}

The duration of the molting cycle and survival decreased in relation to the degree 306 of eyestalk ablation. The capacity of immune response inferred from proPO content and 307 PO activity decreased only in bilaterally ablated shrimp, suggesting higher susceptibility 308 to pathogens. Differences between males and females in biochemical composition of 309 hemolymph in the control group, as well as the sex-related effect of ablation, suggest that 310 metabolic differences between sexes appear before individuals reached reproductive age 311 and weight. 


\section{Acknowledgements}

We are grateful to the Plankton and Marine Biology Departments at CICIMARIPN for their valuable support with equipment. Instituto Politécnico Nacional (IPN) provided a Master's fellowship to J.C.S.H. and additional grants from COFAA-IPN and SIP-IPN for this project. This study was also supported by CONACYT project 43249. We are also grateful to the editor at CIBNOR for modifying the English text, and to two anonymous reviewers for helpful comments.

\section{References}

Ahmed, A., Martin, D., Manetti, A.G.O., Man, S.J., Lee, W.J., Mathiopoulos, K.D., Muller, H.M., Kafatos, F.C., Raikhel, A., 1999. Genomic structure and ecdysone regulation of the prophenoloxidase 1 gene in the malaria vector Anopheles gambie. Proc. Natl. Acad. Sci. 96, 14795-14800.

Beltz, B.S., 1988. Crustacean neurohormones. In: Endocrinology of Selected Invertebrate Types, Invertebrate Endocrinology, Vol. 2. Alan R Liss, New York, pp. 235-258. Benjakul, S., Visessanguan, W., Tanaka, M., 2005. Properties of phenoloxidase isolated from the cephalotorax of Kuruma prawn (Penaeus japonicus). J. Food. Biochem. $29,470-485$.

Bradford, M.M., 1976. A rapid and sensitive method for the quantitation of microgram quantities of protein utilizing the principles of protein-dye binding. Anal. Biochem.72, 248-254. 
Bray, W.A., Lawrence, A., 1992. Reproduction in Penaeus species in captivity. In: Marine Shrimp Culture: Principles and Practices. Fast, A.W., Lester, J. (Ed.) Elsevier, Amsterdam, pp. 93-170.

Carlisle, D.B., 1953. Moulting hormones in Leander (Crustacea, Decapoda). J. Mar. Biol. Assoc. U.K. 32, 289-296.

Chan, S.M., Rankin, S.M., Keeley, L.L., 1990. Effects of 20-hydroxyecdysone injection and eyestalk ablation on the moulting cycle of the shrimp, Penaeus vannamei. Comp. Biochem. Physiol. 96A, 205-209.

Chang, E.S., 1989. Endocrine regulation of molting in crustacea. Aquatic Sci. 1, 131-157. Chang, E.S., 1992. Endocrinology. In: Marine shrimp culture: Principles and Practices. Fast, A.W., Laster, J. (Ed.) Elsevier, Amsterdam, pp. 53-91.

Chang, E.S., O`Connor, J.D., 1988. Crustacean molting. In: Endocrinology of Selected Invertebrate Types, Invertebrate Endocrinology, Vol. 2. Alan R Liss, New York, pp. 259-278.

Chen, J.C., Cheng, S.Y., 1993. Studies on haemocyanin and haemolymph protein levels in Penaeus japonicus based on sex, size and moulting cycle. Comp. Biochem. Physiol. 106B, 293-296.

Chen, J.C., Cheng, S.Y., 1995. Hemolymph oxygen content, oxyhemocyanin, protein levels and ammonia excretion in the shrimp Penaeus vannamei exposed to ambient nitrite. J. Comp. Physiol. 164B, 530-535.

Díaz-Iglesias, E., Brito, R., Hernández, I., 1987. Efectos de la ablación del complejo neurosecretor peduncular en juveniles de langosta, Panulirus argus. II Algúnos aspectos metabólicos. Rev. Inv. Mar. 8, 81-93. 
Fingerman, M., 1995. Endocrine mechanisms in crayfish, with emphasis on reproduction and neurotransmitter regulation of hormone release. Amer. Zool. 35, 68-78.

Gendrop-Funes, V., Valenzuela-Espinoza, E., 1995. Unilateral ablation of Penaeus stylirostris (Stimpson). Ciencias Marinas 21, 401-413.

Hernández-López, J., Gollas-Galvan, T., Vargas-Albores, F., 1996. Activation of the prophenoloxidase system of the brown shrimp (Penaeus californienis Holmes). Comp. Biochem. Physiol. 113, 1-6.

Hiruma, K., Riddiford, L.M., 1993. Molecular mechanisms of cuticular melanization in the tobacco hornworm Manduca sexta (L.) (Lepidoptera: Sphingidae). Intl. J. Insect Morphol. Embryol. 22, 103-117.

Johanson, M.W., Söderhäll, K., 1989. Cellular immunity in crustaceans and the proPO system. Parasitology Today 5, 171-176.

Keller, R., Sedlmeier, D.A., 1988. Metabolic hormone in crustaceans: The hyperglycemic neuropeptide. In: Endocrinology of Selected Invertebrate Types, Invertebrate Endocrinology, Vol. 2. Alan R Liss, New York, pp. 315-326.

Kuo, C.M., Hsu, R.H., Lin, C.Y., 1995. Hyperglycemic effect of dopamine in tiger shrimp, Penaeus monodon. Aquaculture 135, 161-172.

Lachaise, F., Le Reux, A., Hubert, M., Lafont, R., 1993. The molting gland of crustaceans: Localization, activity, and endocrine control (A review). J. Crust. Biol. 13, 198-234.

Lüschen, W., Willing, A., Jaros, P.P., 1993. The role of biogenic amines in the control of blood glucose level in the decapod crustacean, Carcinus meanas L. Comp. Biochem. Physiol. 105C, 291-296. 
Maggioni, D.S., Andreatta, E.R., Hermes, E.M., Barracco, A., 2004. Evaluation of some hemato-immunological parameters in female shrimp Litopenaeus vannamei submitted to unilateral eyestalk ablation in association with a diet supplemented with superdoses of ascorbic acid as a form of immunostimulation. Aquaculture 241, 501-515.

Moullac, G.L., Groumellec, M.L., Ansquer, D., Fraissard, S., Levy, P., Aquacop., 1997. Haematological and phenoloxidase activity changes in the shrimp Penaeus stylirostris in relation with the molt cycle: protection against vibriosis. Fish Shellfish Immun. 7, 227-234.

Müller, H.M., Dinopolus, G., Blass, C., Kafatos, F.C., 1999. A hemocyte-like cell line established from the malaria vector Anopheles gambiae expresses six prophenoloxidase genes. J. Biol. Chem. 274, 11727-11735.

Nan, F.H., Sheen, S.S., Cheng, Y.T., Nan-Chen, S., 1995. The effects of eyestalk ablation on oxygen consumption and ammonia-N excretion of juvenile shrimp_Penaeus monodon. Zool. Stud. 34, 265-269.

Olafsen, J.A., 1988. Role of lectins in invertebrate humoral defense. American Fish. Soc. (Special publication) 18, 189-205.

Otoshi, C.A., Arce, S.M., Moss, S.M., 2003. Growth and reproductive performance of broodstock shrimp reared in a biosecure recirculating aquaculture system versus a flow-through pond. Aquacul Eng. 29, 93-107.

Palacios, E., Carreño, D., Rodrígez-Jaramillo, M.C., Racotta I.S., 1999. Effect of eyestalk ablation on maturation, larval performance, and biochemistry of Penaeus vannamei broodstock. J. Appl. Aquaculture 9, 1-23. 
404 Perazzolo, L.M., Gargioni, R., Ogliari, P., Barranco, M.A.A., 2002. Evaluation of some hemato-immunological parameters in the shrimp Farfantepenaeus paulensis submitted to environmental and physiological stress. Aquaculture 214, 19-33.

Racotta, I.S., Palacios, E., 1998. Hemolymph metabolic variables in response to experimental manipulation stress and serotonin injection in Penaeus vannamei. J. World Aqua. Soc. 29, 351-356.

Racotta, I.S., Hernández-Herrera, R., 2000. Metabolic responses of the white shrimp, Penaeus vannamei, to ambient ammonia exposure. Comp. Biochem. Physiol. 125A, 437-443.

Racotta, I.S., Palacios, E., Ibarra, A.M., 2003. Shrimp larval quality in relation to broodstock condition. Aquaculture 227, 107-130.

Robertson, L., Bray, W., Trujillo, J.L., Lawrence, A., 1987. Practical molt staging of Penaeus setiferus and Penaeus stylirostris. J. World Aqua. Soc. 18, 180-185.

Rosas, C., Fernández, I., Brito, R., Iglesias, E.D., 1993. The effect of eyestalk ablation on the energy balance of pink shrimp, Penaeus notiales. Comp. Biochem. Physiol. 104A, 183-187.

Rosas, C., Bolongaro-Crevenna, A., Sanchez, A., Gaxiola, G., Soto, L., Escobar, E., 1995. Role of the digestive gland in the energetic metabolism of Penaeus setiferus. Biol. Bull. 189, 168-174.

Santos, E.A., Colares, E.O., 1986. Blood glucose regulation in an intertidal crab, Chasmagnatus granulata (Dana, 1851). Comp. Biochem. Physiol. 83A, 673-675. 
425 Santos, E.A., Nery, L.E.M., Manzini, G.C., 1988. Action of the crustacean hyperglycemic hormone of Chasmagnatus granulata (Dana, 1851) (Decapoda: Grapsidae). Comp. Biochem. Physiol. 89A, 329-332.

Santos, E.A., Keller, R., 1993a. Crustacean hyperglycemic hormone (CHH) and the regulation of carbohydrates metabolism: Current perspectives. Comp. Biochem. Physiol. 106A, 405-411.

Santos, E.A., Keller, R., 1993b. Regulation of circulating levels of the crustacean hyperglycemic hormone: evidence for a dual feedback control system. J. Comp. Physiol. 163B, 374-379.

Santos, E.A., Keller, R., 1993c. Effect of exposure to atmospheric air on blood glucose and lactate concentrations in two crustacean species: role of the crustacean hyperglycemic hormone (CHH). Comp. Biochem. Physiol. 106A, 343-347.

Santos, E.A.M., Nery, L.E., Keller, R., Goncalves, A.A., 1997. Evidence for the involvement of the crustacean hyperglycemic hormone in the regulation of lipid metabolism. Physiol. Zool. 70, 415-420.

Söderhäll, K., Smith, V.J., 1986. The prophenoloxidase activating system: the biochemistry of its activation and role in arthropod cellular immunity, with special reference to crustaceans. pp. 208-223. In: Immunity in Invertebrates. (M. Brehelin ed). Springer Verlag, Berlin.

Sorentino, R.P., Carton, Y., Govind, S., 2002. Cellular immune response to parasite infection in Drosophila lymph gland is developmentally regulated. Dev. Biol. $243,65-80$. 
447 Sritunyalucksana, K., Söderhäll, K., 2000. The proPO and clotting system in crustaceans. $448 \quad$ Aquaculture 191, 53-59.

449 Teshima, S. I., Kanazawa, A., Kushio, S., Horinouchi, K., 1988. Lipid metabolism in 450 destalked prawn Penaeus japonicus: Induced maturation and accumulation of $451 \quad$ lipids in the ovaries. Nippon Suisan Gakk. 54, 1115-1122.

452 Vargas-Albores, F., 1995. Sistema de defensa del camarón café (Penaeus californiensis). $453 \quad$ Ciencia 46, 33-45.

454 Vargas-Albores, F., Guzmán-Murillo, M.A., Ochoa, J.L., 1993. Anticoagulant solution 455 for haemolymph collection and prophenoloxidase studies in penaeid shrimp 456 (Penaeus californiensis). Comp. Biochem. Physiol. 106, 299-303.

457 Zou, Z., Wang, Y., Jiang, H., 2005. Manduca sexta prophenoloxidase activating 458 proteinase-1 (PAP-1) gene: Organization, expression, and regulation by immune 459 and hormonal signals. Insect. Biochem. Mol. Biol. 35, 627-636. 
Figures captions

Fig. 1. Effect of eyestalk ablation (EA) on the duration of the molt cycle in Litopenaeus vannamei. (C) control shrimps, (U) unilaterally ablated and (B) bilaterally ablated females and males. Data are presented as mean \pm SD. Following two-way ANOVA (see text for statistical significances), different capital letters on the bars indicate significant difference $(P<0.05)$ between global means (pooled for sex) of the different ablation treatment groups.

Fig. 2. Effect of eyestalk ablation (EA) on hemolymph levels of glucose (a) and lactate (b) in Litopenaeus vannamei. (C) control shrimps, (U) unilaterally ablated and (B) bilaterally ablated females and males. Data are presented as mean \pm SD. Following twoway ANOVA (see text for statistical significances). Only when a significant interaction between EA and sex was obtained (Fig. 2a), individual means (each EA-sex combination) were compared with a posteriori test of Tukey analysis for different sample size. $\alpha=$ 0.05. Otherwise (Fig. 2b) only global means (i.e. pooled means for EA) were compared and significant differences are indicated with capital letters.

Fig. 3. Effect of eyestalk ablation (EA) on hemolymph levels of triglycerides (a) and cholesterol (b) in Litopenaeus vannamei. (C) control shrimps, (U) unilaterally ablated and (B) bilaterally ablated females and males. Data are presented as mean \pm SD. See figure 2 for statistical details. 
483 Fig. 4. Effect of eyestalk ablation (EA) on hemolymph levels of protein in Litopenaeus

484 vannamei. (C) control shrimps, (U) unilaterally ablated and (B) bilaterally ablated

485 females and males. Data are presented as mean \pm SD. See figure 2 for statistical details.

486

487 Fig. 5. Effect of eyestalk ablation (EA) on hemolymph prophenoloxidase content (a),

488 phenoloxidase activity (b) and total haemocytes count (THC) (c) in Litopenaeus

489 vannamei. (C) control shrimps, (U) unilaterally ablated and (B) bilaterally ablated

490 females and males. Data are presented as mean \pm SD. See Fig. 2 for statistical details. 
Figure(s)
Click here to download high resolution image

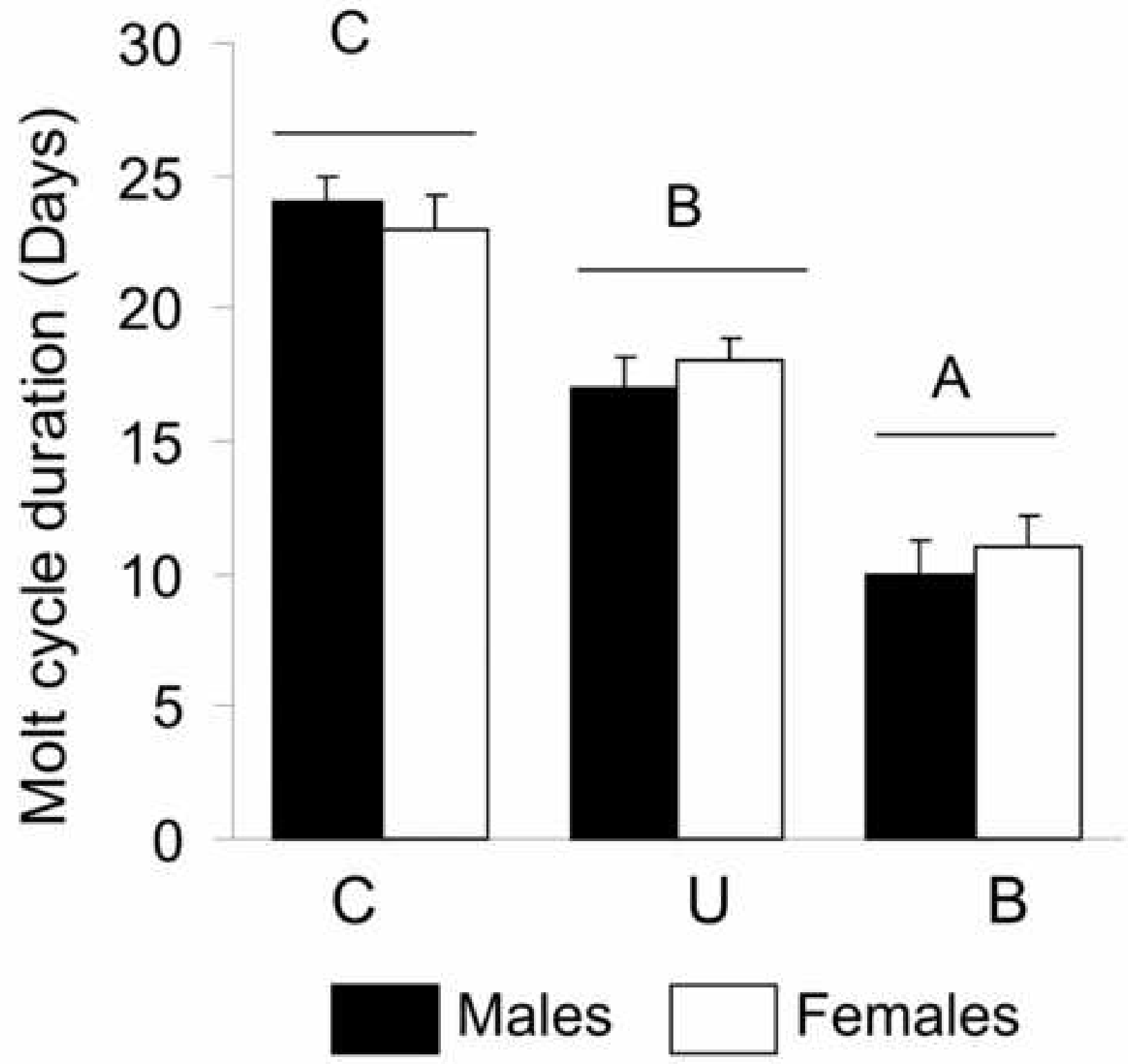


Click here to download high resolution image
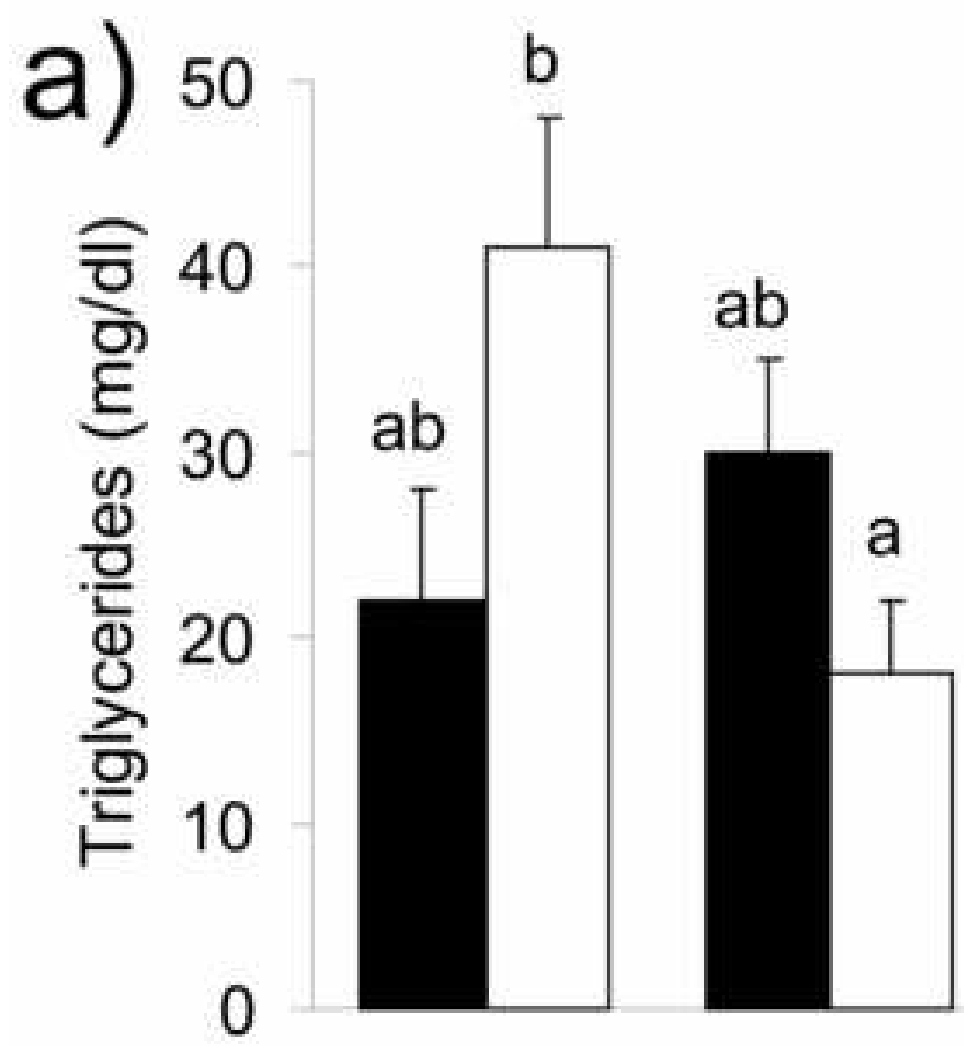

$a b \quad a b$
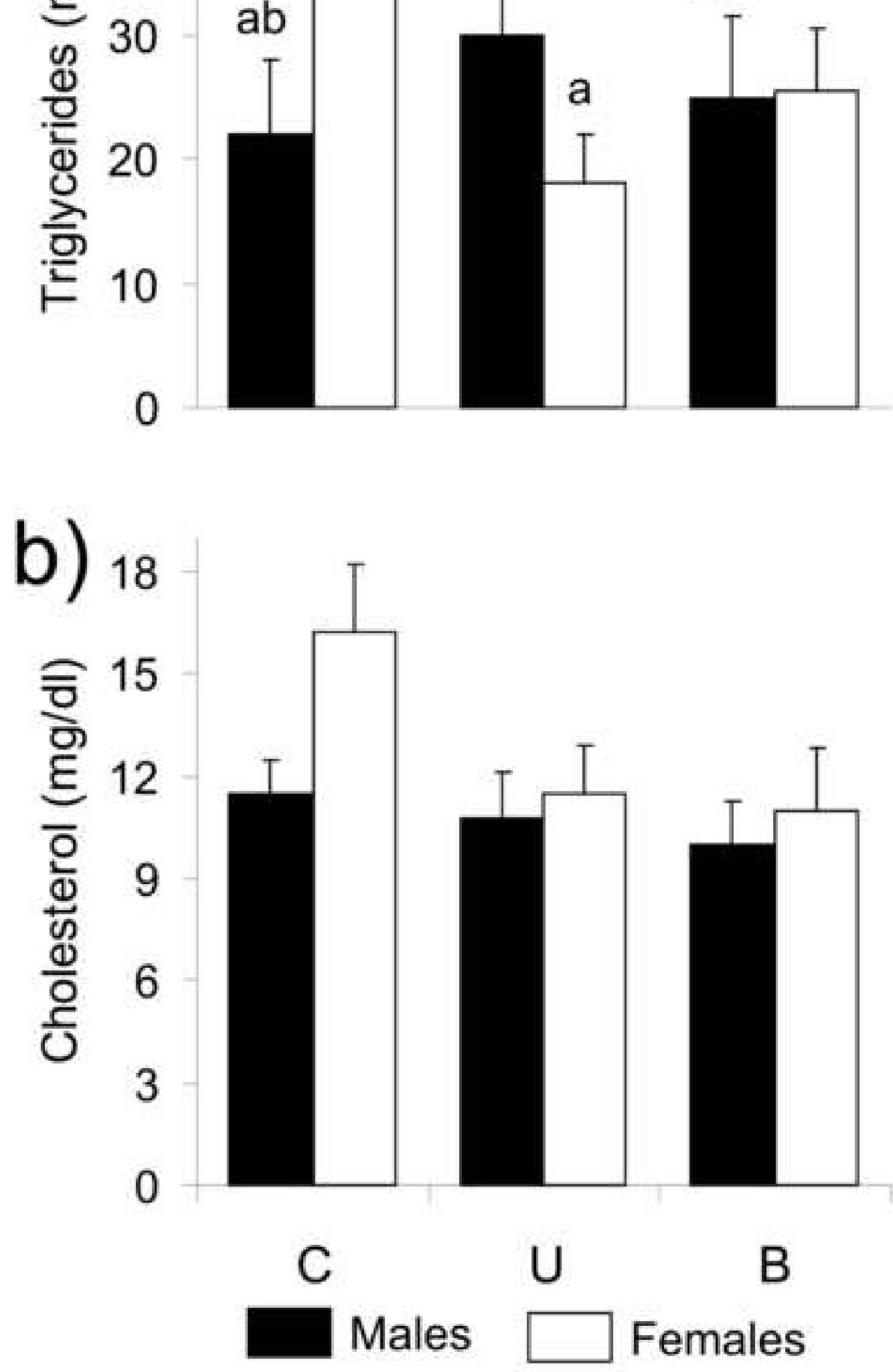
Figure(s)

Click here to download high resolution image
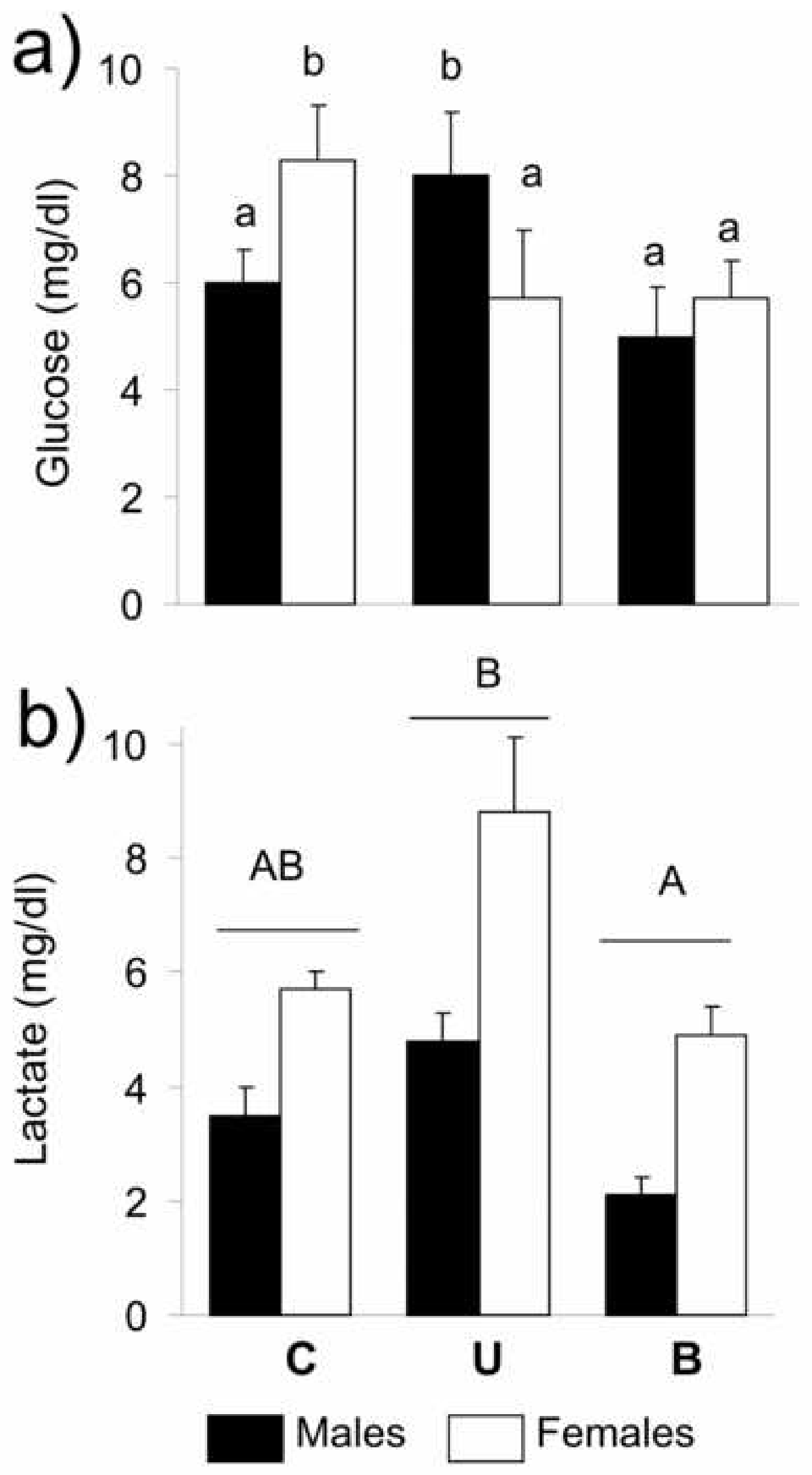
Figure(s)
Click here to download high resolution image

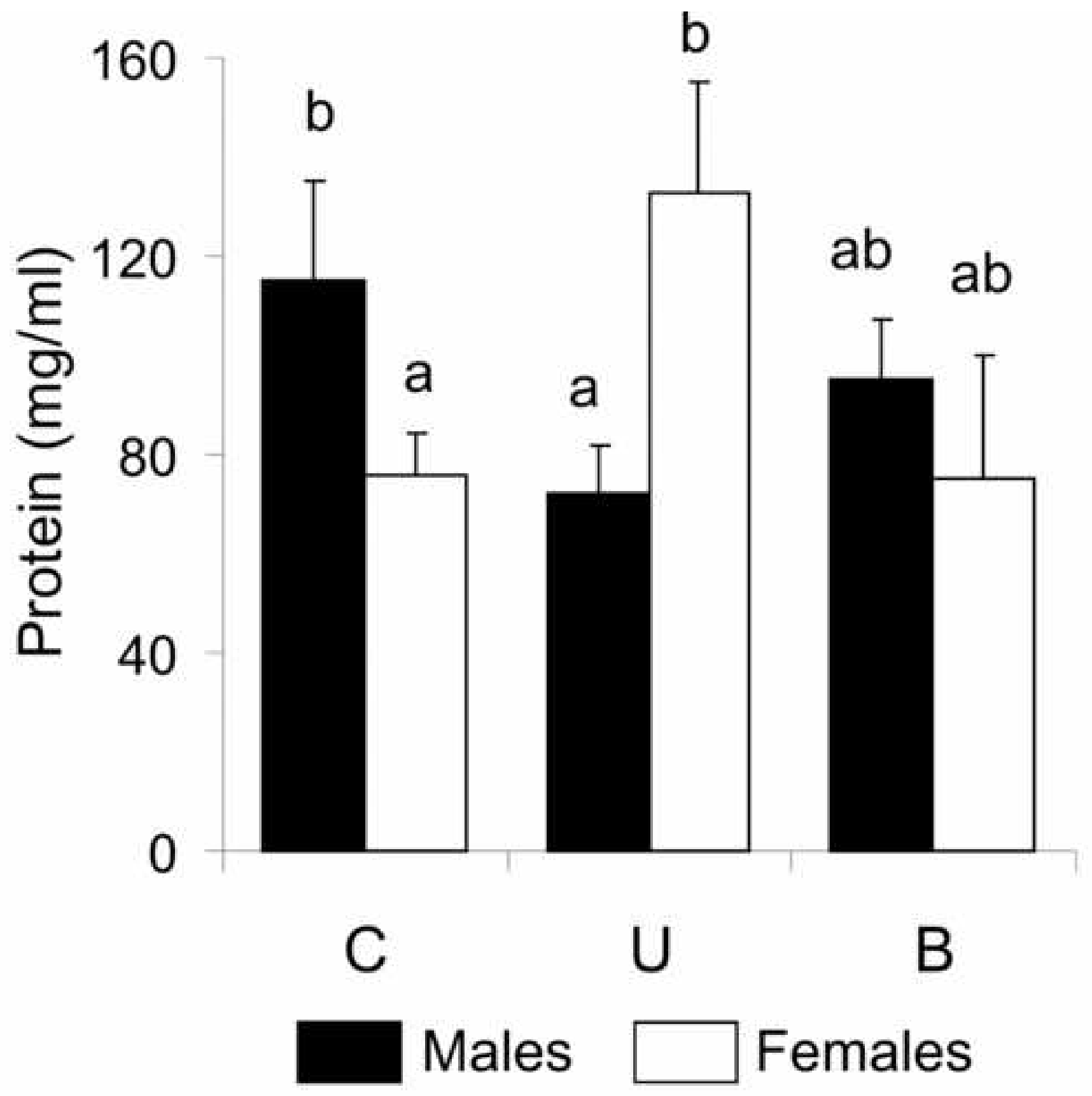


Click here to download high resolution image
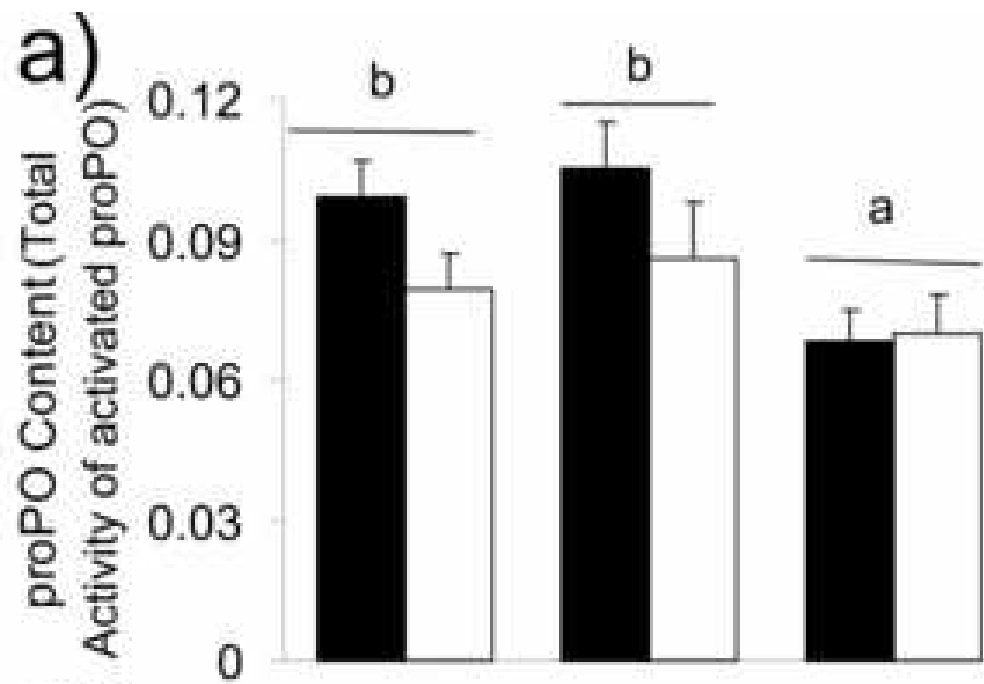

b)

0.05

b

b

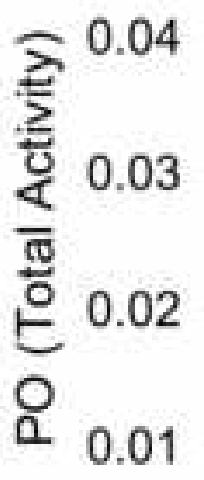

c)
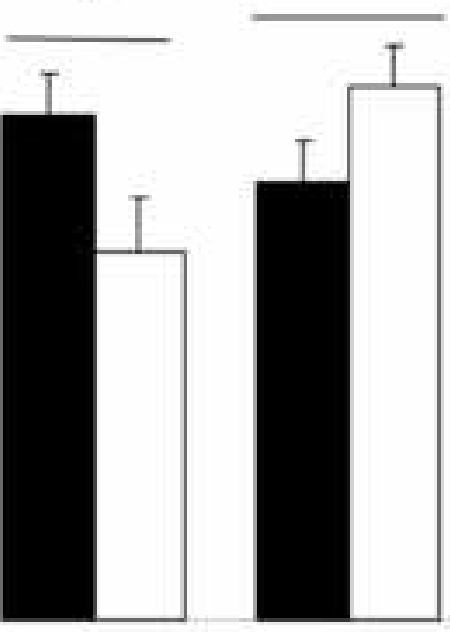

a

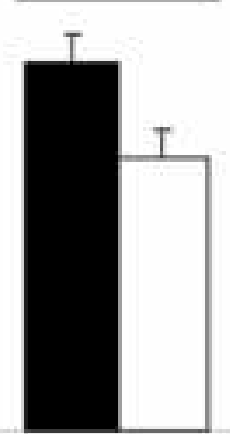

35

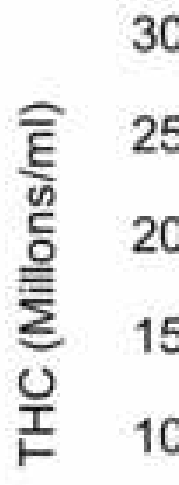

5

0
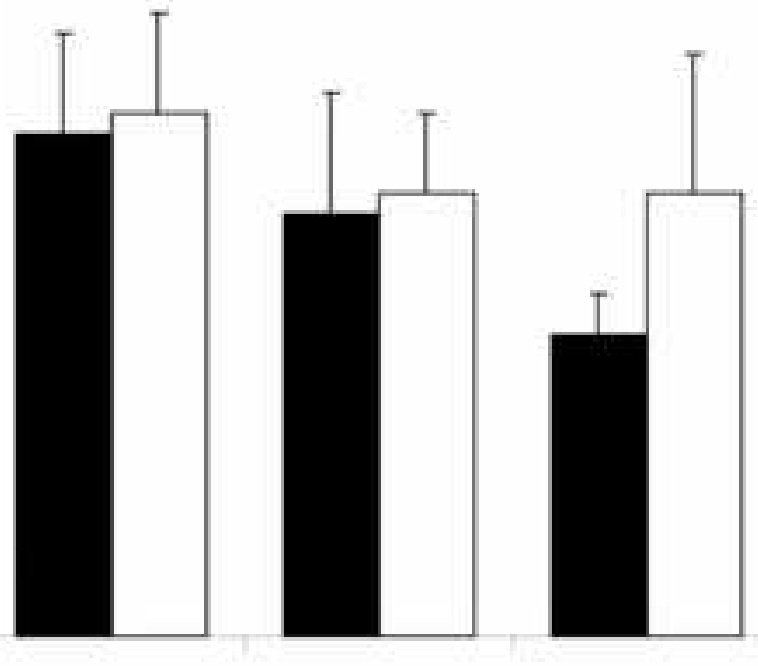

C

U

B 
Dear Dr. Donaldson

I am sending you back the revised version of the manuscript A QUA- D-07-00020), "Effect of unilateral and bilateral eyestalk ablation in Litopenaeus vannamei males and females on several metabolic and immunologic variables" by J.C. Sainz-Hernández, I.S. Racotta, S. Dumas and J. Hernández-López submitted to A quaculture.

Some specific corrections are highlighted with yellow in the revised manuscript. However complete sections were rewritten as indicated. All suggestions of referees were addressed as indicated below:

Reviewer No. 1

English language was revised by our institutional editor whose first language is English

A) M ethods and Results sections

- Time of hemolymph sampling was now indicated (line 91).

- We used a calibration curve and it is now indicated (line 103).

- We did not evaluate the different groups in different times; the first sentence of the results section was rephrased for clarity to state that the duration of the molt cycle was different between groups (lines 146-147).

- Conventional signs $(P<0.05)$ were used to indicate significant differences throughout the whole text (also suggested by Reviewer No. 2).

- All figures were re-drawn as suggested. Results were re-written according to the new order and style was changed for clarity.

B) Discussion

In general discussion was shortened and rewritten with a more integrative perspective and less speculation.

- The first two paragraphs were deleted as suggested

- It is now specified that there is a decrease in the duration of the molt cycle (line 178 and line 317)

- The discussion on the immune condition was in general improved and a consideration about the participation of PO in the tanning process during the molt cycle was now considered (lines 237-243).

- Causes of mortality were reconsidered and severe physiological disruptions including nervous system damage are now included (201-203).

- Mistakes in the literature were corrected

Reviewer No. 2

- One sentence was deleted from the abstract as suggested

- The section of hormonal control of proPO system in the Introduction was rewritten (lines 52-60)

- Register of molting occurrence was confusing in the previous version of the MS; a more detailed description of shrimp and exuviae marking was now included in the corrected version (see lines 80 to 83 )

- All style corrections were done, particularly for the Results and Discussion sections that were practically rewritten. 